\title{
PROSPECÇÃo DE MERCADO DE ENERGIA FOTOVOLTAICA NA REGIÃO DE CAMPINAS
}

Nome do Autor (a) Principal

Carolina Braz Góes

Nome (s) do Coautor (a) (s)

Bruno Wilmer Fontes Lima; Gilberto Eiji Ivamoto

Nome (s) do Orientador (a) (s)

Gilberto M. Jannuzzi

Instituição ou Empresa

Universidade de Campinas e Inova (Agência de Inovação da UNICAMP)

Instituição (s) de Fomento

O presente trabalho foi realizado com apoio do CNPq (Conselho Nacional de Desenvolvimento Científico e Tecnológico - Brasil)

E-mail de contato: carolina.braz.goes@gmail.com

Palavras-chave: Energia Fotovoltaica, Mercado Nacional, Prospecção.

\subsection{INTRODUÇÃO}

As tendências do mercado e a prospecção do mesmo, quando definido como alvo por uma determinada empresa, indicam hipotéticos cenários futuros. Dessa maneira é importante na gestão e atualização do plano de negócios.

Segundo SILVA, et al (2014) o planejamento energético ganhou notoriedade sobretudo após a crise do petróleo na década de 70.

Planejamento e estratégias são realmente importantes segundo JANNUZZI (2002) porque quando uma infraestrutura é desenvolvida, torna-se difícil de ser alterada em um espaço curto de tempo.FERNANDO (2010) apud BARB, et al (2015) também aponta a importância do planejamento energético elaborado também pelo Estado, principalmente pelas questões de infraestrutura. 


\section{Periódica Eletrânica

Para entender a situação do mercado nacional das energias renováveis, especificadamente em energia fotovoltaica, é necessário analisar aspetos gerais dessa energia e seu mercado no mundo. De acordo com CGEE (2005) o uso de cenários é uma ferramenta interessante por explicitar várias hipóteses.

Ainda na criação de possíveis cenários futuros para o mercado de energia fotovoltaica no Brasil é importante analisar a perspectiva governamental, empresarial e popular nacional sobre $o$ assunto.

De acordo com JANNUZZI, et al (2004) prospecção pode ser visualizada por um viés simples, a partir de sua afirmação "é um levantamento de uma relação de tecnologias e atividades de suporte para seu desenvolvimento de maneira a atender as expectativas e demandas de uma sociedade". Segundo a CGEE (2005) para efetuar o exercício de prospecção tecnológica é necessário compreender a dinâmica social e técnica e tem como objetivo identificar tecnologias emergentes e pesquisas estratégicas.

\subsection{JUSTIFICATIVA}

A pesquisa de prospecção de mercado é uma ferramenta importante na área de gestão de negócios. Ignorar essa ferramenta pode justificar investimentos desnecessários. A prospecção facilita que as tomadas de decisões sejam positivas, conforme resultados de pesquisas antecipadas.

Segundo JANNUZZI, et al (2004):

"A prospecção tecnológica é um instrumento para se conhecer as possibilidades e oportunidades de investimentos em P\&D em áreas que podem ser importantes para 0 desenvolvimento econômico e social do país. Um trabalho de prospecção tem como um de seus objetivos principais oferecer subsídios para financiamento de atividades de $\mathrm{P} \& \mathrm{D}(\ldots)$ ".

Segundo TIOZO (2013): "identificar as partes interessadas é um dos importantes fatores para gerenciamento de projetos". 


\title{
Periódica Eletrânica

\subsection{DESENVOLVIMENTO}

A prospecção de mercado, assim como outra estratégia empresarial, necessita de definições, planos, planejamentos bem estruturado para que investimentos sejam bem aplicados.

De acordo com QUADROS (2008):

\begin{abstract}
Mapeamento e prospecção de oportunidades e ameaças, olhar para o futuro, compreendendo ferramentas de identificação de oportunidades de mercado, riscos e oportunidades tecnológicas e monitoramento do ambiente competitivo e regulatório, com o intuito de criar uma inteligência que oriente a geração de novos $\operatorname{projetos}(\ldots)$.
\end{abstract}

ABINEE (2012); MME (2009) e a CCGE (2010) apud EPE (2012) acreditam que o Brasil esta em um período de florescimento de uma nova indústria, ainda que de forma tímida e concentrada na oferta de serviços para um pequeno mercado.

A inovação tecnológica é um desafio, sobretudo para uma pequena empresa, mas é cada vez mais vista como o fator chave para a competitividade de um país. (OECD, 2001) apud INACIO et al (2012)

A presente pesquisa utilizou como estudo de caso uma empresa de base tecnológica. SANTOS et al (1986, p. 4) apud INACIO et al (2012) afirmam que "as empresas de tecnologias avançadas são aquelas criadas para fabricar produtos ou serviços que utilizam alto conteúdo tecnológico ".

É necessário então definir mercado de interesse para adequar inovação. Pesquisa e prospecção do mercado definido é parte do processo de inovação.

\subsection{METODOLOGIA}

A pesquisa foi realizada como estudo de caso de uma empresa. Para essa etapa introdutória utilizou-se a ferramenta SWOT (Fraquezas, Oportunidades, Forças e Ameaças). O primeiro passo, segundo APPIO (2009) é analisar o ambiente em que a organização esta inserida a elaborar uma avaliação.

Também foi proposto e elaborado o CANVAS (The business model Canvas) que tem como finalidade ajudar na organização empresarial.

$\mathrm{Na}$ fase de foco da pesquisa no mercado definiu-se a utilização da entrevista estruturada na metodologia "face to face" com empresa, que atua na área de energia fotovoltaica. Antes de iniciar a prospecção é necessário conhecer sobre as 
experiências da empresa. Dessa maneira é possível aproveitar seus conhecimentos sobre tendência de mercado. Resultado dessa etapa: mercado alvo para prospecção: colégios da cidade de Campinas, São Paulo.

A metodologia dessa etapa não utilizou-se bases em hipóteses, sendo assim é considerada exploratória quantitativa. Segundo (RICHARDSON, 1989, p 26) apud APPIO, et al (2009) a pesquisa exploratória é utilizada "quando não se tem informação sobre determinado tema e se deseja conhecer o fenômeno". Elaborou-se questionários para entrevistas com o definido mercado alvo, através de enquetes virtuais no e-mail onde abordou-se sobre existência ou não de interesse, possibilidades teóricas de aquisição, analise do grau de entendimento da energia solar, tanto da questão ambiental quanto econômica, ação inovadora para o mercado, economia e outro uso, como por exemplo, educação.

\subsection{RESULTADOS}

Entre Outubro de 2014 e Fevereiro de 201588 colégios de Campinas receberam contato, informações sobre a pesquisa e um questionário sobre a relação do colégio com a energia solar. Desses, 4 responderam o questionário.

Gráfico 1. Prospecção de energia solar em colégios de Campinas

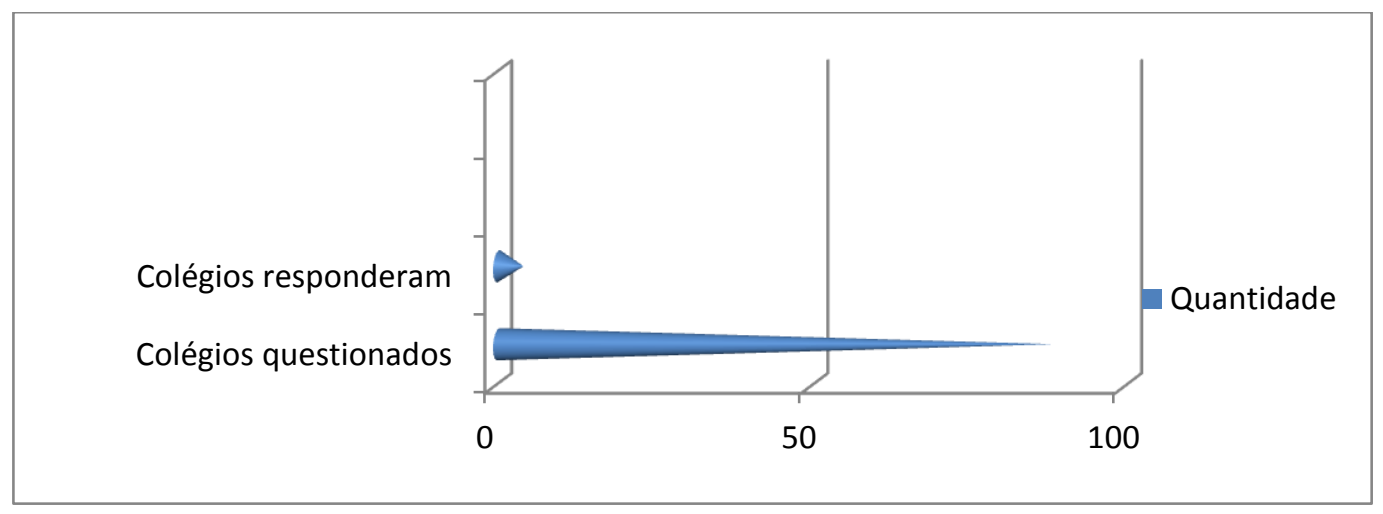

Fonte: Autoria própria, 2015. 
Gráfico 2. Motivos de interesse na energia solar entre os 4 colégios.

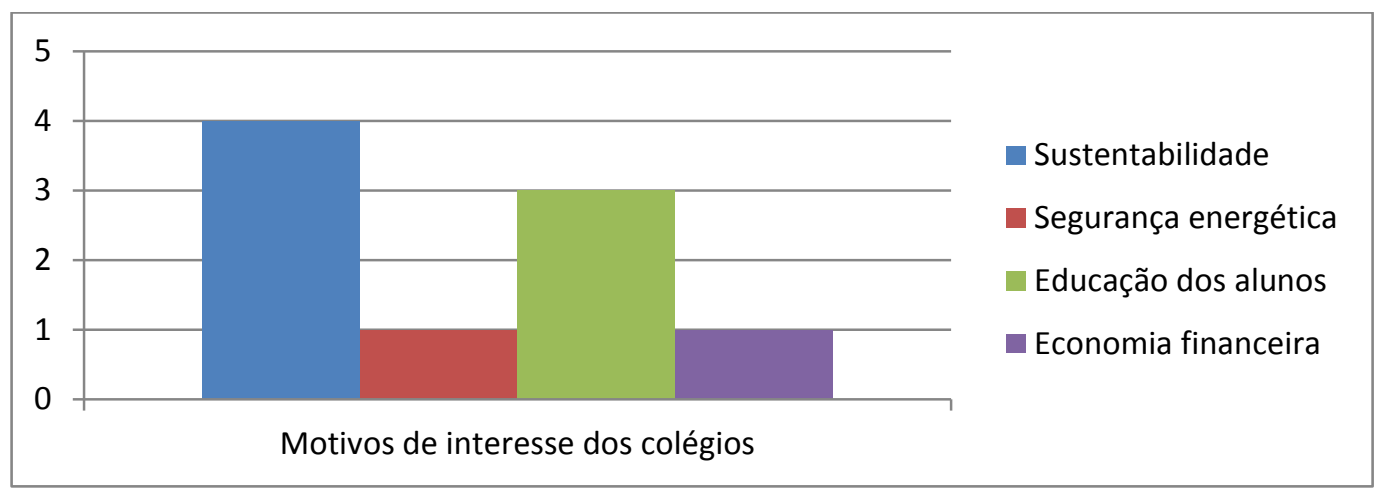

Fonte: Autoria própria, 2015.

\subsection{CONCLUSÃO}

O motivo do não retorno dos 84 colégios não pode ser declarado definitivamente, mas alguns relatos citaram o fato de que o colégio contemporâneo tem grande preocupação com número de estudantes aceitos no sistema de seleção de universidades (vestibular), ignorando atividades extracurriculares, com abordagens teóricas e práticas, como seria o caso de aproveitar o sistema para a aprendizagem dos educandos e educadores. Outro motivo apresentado foi o fato de franquias de sistemas de ensino proibirem atividades diferentes das oferecidas pelo sistema e também o monopólio de colégios na região, que dificulta a diversidade de opiniões e tomadas de decisões, o que também e influencia na pesquisa.

Os resultados concluem de modo positivo para pesquisa, pois indica que esse mercado não esta em bom momento para a inserção de investimentos dessa tecnologia como pratica. Por outro lado apronta necessidade de investimentos como conscientização ambiental, desenvolvimento de incentivos, informativos sobre possibilidades de financiamentos e facilidades de aquisição de tecnologias sustentáveis.

\subsection{REFERÊNCIAS}

ABINEE. Propostas para Inserção da Energia Solar Fotovoltaica na Matriz Elétrica Brasileira. Associação Brasileira da Indústria Elétrica e Eletrônica, São Paulo. 2012.

APPIO, Jucélia et al. Análise SWOT como diferencial competitivo: um estudo exploratório na Cooperativa Muza Brasil.Revista Interdisciplinar Científica Aplicada, v. 3, n. 3, p. 1-18, 2009 


\section{Periódica Eletrânica

BARB, C., A., SEHNEM. S., BENCKE, F., F. Energia fotovoltaica como matriz energética sustentável em organizações. Revista Gestão Sustentável Ambiental. Florianópolis, v. 3, n. 2, p. 178 - 203. out.2014/mar.2015

CGEE. Prospecção Tecnológica em Energia. Centro de Gestão e Estudos Estratégicos.

Brasília, 2005.

EPE. (2012). Análise da Inserção da Geração Solar na Matriz Elétrica Brasileira. Empresa de Pesquisa Energética, Rio de Janeiro.

INACIO JR., E.; QUADROS, R. C; GAVIRA, M. Proposição de um novo método de seleção de micro, pequenas e médias empresas de base tecnológica (MPEBT). Revista de Empreendedorismo e Gestão de Pequenas Empresas, v. 1, n. 2, 2012.

JANNUZZI, G. M. Aumentando a eficiência nos usos finais de energia no Brasil. Unicamp. Campinas, SP. 2002

JANNUZZI, G., M., MACEDO., I., ZACKIEWICZ., M., SAN'T ANA., P., H., M. A Prospecção Tecnológica em Energia e a Pesquisa e Desenvolvimento no Brasil: Elementos para uma Estratégia. Energy Discussion. Paper no 2.64.2/04, 2004. Campinas, SP.

JANNUZZI, G., M., SANT ANA. P., H., M., GOMES, R., PACCOLA. J., A. Energias do futuro. International Energy Initiative, 2008.

QUADROS, Ruy. Aprendendo a Inovar: Padrões de Gestão da Inovação Tecnológica em Empresas Industriais Brasileiras. 2008. Grupo de Estudos de Empresas e Inovação. UNICAMP.

TIOZO, Carla. Métodos de gestão de projetos aplicados aos programas de eficiência energética da ANEEL. Energy Discussion Paper. № 2.83.3/2013.

SILVA, S., S., F., CÂNDIDO, G., A., RAMALHO, A., M., C. Planejamento energético nacional: um olhar para a variável ambiental. Universidade do Estado do Rio de Janeiro, Rio de Janeiro, Revista Polêm!ca, v. 13, n.3 , julho/agosto/setembro de 2014 